\title{
Research, Design and Development a Model Solar Autonomous Underwater Vehicles
}

\author{
Tuan Nguyen Van ${ }^{1,2}$, Phong Dinh Van $^{3}$, Hung Nguyen $\mathrm{Chi}^{4}$, Hoang Tran Viet \\ ${ }^{1}$ Hanoi University of Science and Technology, Vietnam, tuan.nguyenvan@phenikaa-uni.edu.vn \\ ${ }^{2}$ Phenikaa University, Vietnam, tuan.nguyenvan@ phenikaa-uni.edu.vn \\ ${ }^{3}$ Hanoi University of Science and Technology, Vietnam, phong.dinhvan@ hust.edu.vn \\ ${ }^{4}$ Hanoi University of Science and Technology, Vietnam, hung.nguyenchi@hust.edu.vn \\ ${ }^{5}$ Hanoi University of Science and Technology, Vietnam, hoangprohp1999@gmail.com
}

Received Date : August 02, 2021 Accepted Date : August 21, 2021 Published Date : September 07, 2021

\begin{abstract}
Autonomous Underwater Vehicle (AUV) has become the main tool for exploring the oceans in the fields of science, the military and the marine economy... However, the energy problem for AUV has always been of interest to many researchers. AUV's missions are time-limited by constraints of onboard vehicle power. Most missions are therefore short, from 4 to 15 hours duration. Solar energy is an effective renewable energy source and has increasingly been used in many fields. We can see that if the Solar Autonomous Underwater Vehicles (S-AUV) has the little surface area then the efficiency of solar collector is low. Hence, we need to optimize the structure of S-AUV. When designing a SAUV in particular and an AUV in general, one of the first concerns is structural shapes, energy and propulsion systems. However, the problem for S-AUV shaped structure is extremely important, requiring the designer to optimize between increased size solar wing and collected solar energy. This paper discusses the use of Computational Fluid Dynamics (CFD) to determine the resistance of S-AUV when receiving solar energy. Reducing the drag and increasing the ability while collecting solar energy are the purpose of this research. The authors developed a model of S-AUV with retractable wings and evaluate the efficiency of solar energy collection. The hydrodynamic equations with the predefined conditions were modeled and solved.
\end{abstract}

Key words : Solar Autonomous Underwater Vehicles; Computational Fluid Dynamics; CFD; S-AUV.

\section{INTRODUCTION}

In recent years the Autonomous Underwater Vehicle (AUV) has become the main tool for exploring the oceans in the fields of science, the military, and the marine economy. However, the energy problem for AUV has always been of interest to many researchers. AUV missions are time-limited by constraints of on-board vehicle power. AUV is a very useful device in sea work, especially deep, offshore waters, polluted water areas $[1,2]$. This is a self-propelled diving device, so the energy supply to the device is always a problem to be solved. Since the power source determines the operating range of AUV [3], the longer the operating time, the greater the workability of the device, the more tasks it can perform. Most missions are therefore short, of 4 to 12 hours duration. AUV is a device that operates in a water environment, so the energy wasted when operating is directly proportional to the speed of the AUV and therefore the range of AUV will depend on the speed of the device. According to research [6], this range is given by the equation below:

$$
R=\frac{E}{K_{d}} \cdot \frac{1}{v^{2}}
$$

Inside:

$$
\begin{aligned}
& R: \text { AUV operating range }(\mathrm{m}) \\
& E \text { : Available Energy }(\mathrm{J}) \\
& K_{d}: \text { Drag coefficient } \\
& v: \text { Speed of AUV }(\mathrm{m} / \mathrm{s})
\end{aligned}
$$

There are several ways to increase the range of self-propelled diving equipment such as: developing high-capacity batteries like fuel cells $[4,5]$, fuel cell hybrid electric [7],... Use natural energy sources such as wind, flow, solar energy [8], or combine wind and solar energy [9].

Worldwide, there have also been studies of integrating additional energy systems for an AUV self-propelled diving device. As a solar supplement system [10]. Some calculations, preliminary analysis of integrated solar battery system on AUV have been studied since the 90s of the last century [11], [12]. Some studies on the ability to move for a long time, to serve the assessment and monitoring on the ocean. Using solar panels and methanol fuel cells in combination with the neural neural network architecture in controlling intelligent orbits [13]. S-AUV are designed for monitoring, surveillance, or storage facilities, where real-time two-way communication is critical.

Vietnam has a large sea area. Furthermore, Vietnam is a tropical equatorial country. Hours of sunshine per year are over 2,000 hours. 
Tuan Nguyen Van et al., International Journal of Emerging Trends in Engineering Research, 9(9), September 2021, 1217 - 1223

Table 1: Parameters of solar radiation intensity in Vietnam (Data of National Meteorological Center - Vietnam)

\begin{tabular}{|c|c|c|c|}
\hline No & $\begin{array}{c}\text { Area of } \\
\text { Vietnam }\end{array}$ & $\begin{array}{c}\text { Solar energy } \\
\text { density } \\
\left(\boldsymbol{k W h} / \mathbf{m}^{2} / \text { day }\right. \\
)\end{array}$ & $\begin{array}{c}\text { Average hours } \\
\text { of sunshine } \\
\text { (hour/year })\end{array}$ \\
\hline 1 & Northeast & $3.3-4.1$ & $1,500-1,800$ \\
\hline 2 & $\begin{array}{c}\text { North } \\
\text { West }\end{array}$ & $4.1-4.9$ & $1,890-2,102$ \\
\hline 3 & $\begin{array}{c}\text { North } \\
\text { Central region }\end{array}$ & $4.6-5.2$ & $1,700-2,000$ \\
\hline 5 & $\begin{array}{c}\text { South Central } \\
\text { and Central } \\
\text { Highlands }\end{array}$ & $4.9-57$ & $2,000-2,600$ \\
\hline 5 & $\begin{array}{c}\text { Southern } \\
\text { Region }\end{array}$ & $4.3-4.9$ & $2,200-2,500$ \\
\hline Average of & 4.6 & 2,000 \\
\hline
\end{tabular}

However, when integrating solar power, it will affect the shape and size of the device. Therefore, the problem arises to optimize the shape so that the drag is the smallest in the process of moving. Therefore, the research team introduced a new design with solar wings that could change during the operation of S-AUV. From time to time, the energy wings will be opened to receive solar energy, when the solar energy in the end of the day, the energy wing will close. S-AUV will operate when the wing closes, which reduces drag on the device. CFD tools useful in analyzing test before prototype [15]. Tool CFD to analyze the flow field around the hull and perform successful computations of viscous drag have found interesting applications in ship design $[16,17,18]$.

\section{DESIGN MODEL OF S-AUV}

There are also a number of studies about S-AUV, initially for the significant results such as increased range and duration. When designing a S-AUV in particular and an AUV in general, one of the first concerns is structural shapes, energy and propulsion systems. However, the problem for S-AUV shaped structure is extremely important, requiring the designer to optimize between size increase solar wing and solar energy collected. Therefore, the author proposed to build a S-AUV integrated power wing capable of transforming when receiving solar energy and when moving. To reduce the drag and to increase the ability to collect solar energy. The S-AUV 3D model is designed using SolidWorks software as Figuge $(1,2)$ and Table 2 . The solar wing can be opened and closed.

Table 2: Size of S-AUV model

\begin{tabular}{|c|l|}
\hline Parameters & Value \\
\hline Length & $1,450 \mathrm{~mm}$ \\
\hline Diameter max & $300 \mathrm{~mm}$ \\
\hline
\end{tabular}

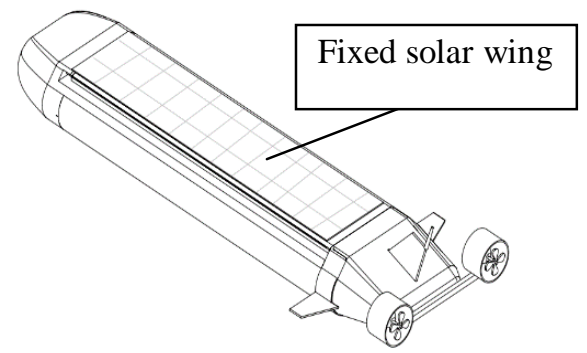

Figure 1: S-AUV in closed solar wing case

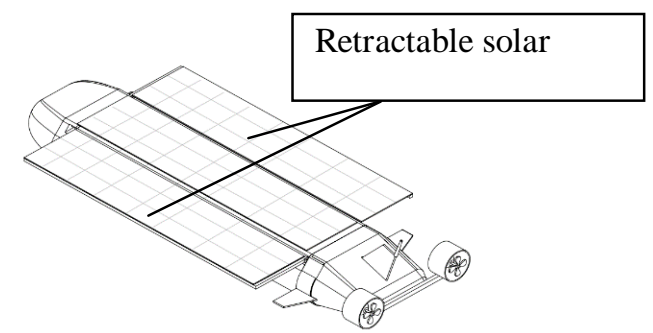

Figure 2: S-AUV in opened solar wing case

\section{MOTION EQUATION FOR S-AUV}

The dynamic model of the S-AUV is built on the basis of mechanical theory, the principles of kinetics and statics. Hydrodynamic models of the S-AUV are used to design control systems for the S-AUV that meet specific objectives such as motion trajectory control, dive depth control, direction control, ... In general, the movement of S-AUV can be represented by equations of motion with six degrees of freedom [19]. Parameters such as the direction of motion, force and torque, speed and position for the S-AUV are shown in Table 3 and Figure 3.

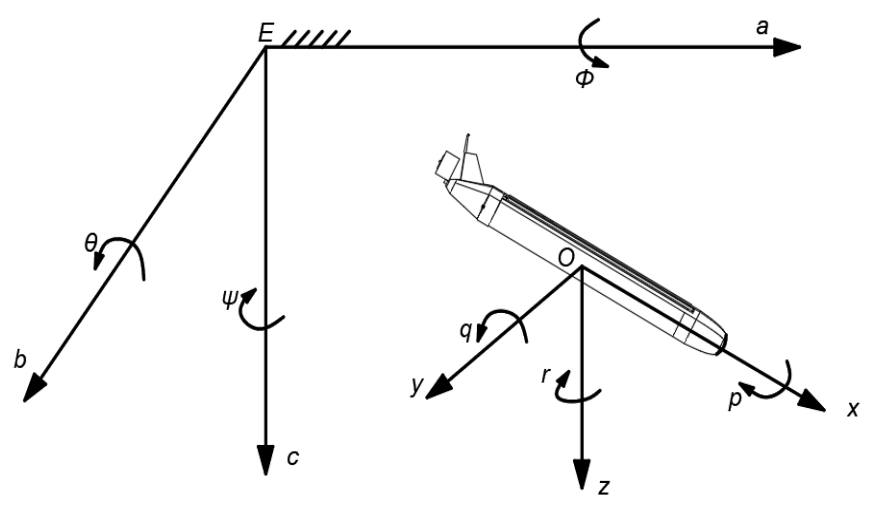

Figure 3: The dynamic coordinate system and fixed coordinate system 
Tuan Nguyen Van et al., International Journal of Emerging Trends in Engineering Research, 9(9), September 2021, 1217 - 1223

Table 3: Parameter symbols are represented in dynamic and fixed coordinate systems

\begin{tabular}{|c|c|c|c|c|}
\hline DOF & Motion & $\begin{array}{c}\text { Forces and } \\
\text { moments }\end{array}$ & $\begin{array}{c}\text { Velocit } \\
\mathbf{y}\end{array}$ & $\begin{array}{c}\text { Position } \\
\text { and } \\
\text { Euler } \\
\text { angles }\end{array}$ \\
\hline 1 & Surge & $\mathrm{X}$ & $\mathrm{u}$ & $\mathrm{x}$ \\
\hline 2 & Sway & $\mathrm{Y}$ & $v$ & $\mathrm{y}$ \\
\hline 3 & Heave & $\mathrm{Z}$ & $\mathrm{w}$ & $\mathrm{z}$ \\
\hline 4 & Roll & $\mathrm{K}$ & $\mathrm{p}$ & $\phi$ \\
\hline 5 & Pitch & $\mathrm{M}$ & $\mathrm{q}$ & $\theta$ \\
\hline 6 & Yaw & $\mathrm{N}$ & $\mathrm{r}$ & $\psi$ \\
\hline
\end{tabular}

The S-AUV was considered as a solid object. So the motion equation of S-AUV is represented by a set of vectors [19]:

$$
M_{R B} \dot{v}+C_{R B}(v) v=\tau_{R B}
$$

Inside:

$v=[\mathrm{u}, \mathrm{v}, \mathrm{w}, p, q, r]^{T}$ is linear and angular velocity vector in the $O-x y z$ coordinates

$$
\tau_{R B}=[\mathrm{X}, \mathrm{Y}, \mathrm{Z}, \mathrm{K}, \mathrm{M}, \mathrm{N}]^{T} \text { is force and moments vector in }
$$

the $O-x y z$ coordinates

$M_{R B}$ is inertial matrix in S-AUV system

$C_{R B}(v)$ is Coriolis and centripetal force matrix in S-AUV system

Inertial matrix in S-AUV

$$
M_{R B}=\left[\begin{array}{cccccc}
m & 0 & 0 & 0 & m z_{g} & -m y_{g} \\
0 & m & 0 & -m z_{g} & 0 & m x_{g} \\
0 & 0 & m & m y_{g} & -m x_{g} & 0 \\
0 & -m z_{g} & m y_{g} & I_{x} & I_{x y} & I_{x z} \\
m z_{g} & 0 & -m x_{g} & I_{\mathrm{yx}} & I_{y} & I_{y z} \\
-m y_{g} & m x_{g} & 0 & I_{z x} & I_{z y} & I_{z}
\end{array}\right]
$$

Coriolis and centripetal force matrix in S-AUV:

$$
C_{R B}=\left[\begin{array}{cccccc}
0 & -m r & m q & m\left(y_{g} q+z_{g} r\right) & -m x_{g} q & -m x_{g} r \\
m r & 0 & -m p & -m y_{g} p & m\left(z_{g} r+x_{g} p\right) & -m y_{g} r \\
-m q & m p & 0 & -m z_{g} p & -m z_{g} q & m\left(x_{g} p+y_{g} q\right) \\
-m\left(y_{g} q+z_{g} r\right) & m y_{g} p & m z_{g} p & 0 & I_{z x} p+I_{z y} q+I_{z} r & -I_{y x} p-I_{y} q-I_{y z} r \\
m x_{g} u & -m\left(z_{g} r+x_{g} p\right) & m z_{g} q & -I_{z x} p-I_{z y} q-I_{z} r & 0 & I_{x} p+I_{x y} q+I_{x z} r \\
m x_{g} r & m y_{g} r & -m\left(x_{g} p+y_{g} q\right) & I_{y x} p+I_{y} q+I_{y z} r & -I_{x} p-I_{x y} q-I_{x z} r & 0
\end{array}\right] \text { (4) }
$$

(1) Static force vector $\tau_{g}$ (gravity and buoyancy of S-AUV)

(2) Hydrodynamics vector of S-AUV (include force $\tau_{A}$ by added mass and damping force $\tau_{V}$ )

(3) Control vector (include pushing force $\tau_{\text {prop }}$ and steering wheel force $\tau_{R}$ )

Static force $\tau_{g}$ reflect the effects of weight and buoyancy of S-AUV. Specifically, weight of S-AUV is $\mathrm{W}=\mathrm{mg}$ and buoyancy is $B=\rho . \nabla g$; with $\rho$ is specific gravity of the liquid in surround, $\nabla$ is sum of moving volume of S-AUV, $g$ is the acceleration of gravity, $m$ is mass of S-AUV.

Therefore, $\tau_{g}$ is given by the below equation:

$$
\tau_{g}=\left[\begin{array}{c}
X_{g} \\
Y_{g} \\
Z_{g} \\
K_{g} \\
M_{g} \\
N_{g}
\end{array}\right]=-\left[\begin{array}{c}
-(\mathrm{W}-B) \mathrm{s}(\theta) \\
(\mathrm{W}-B) \mathrm{c}(\theta) \mathrm{s}(\phi) \\
(\mathrm{W}-B) \mathrm{c}(\theta) \mathrm{c}(\phi) \\
\left(y_{g} \mathrm{~W}-y_{B} B\right) \mathrm{c}(\theta) \mathrm{c}(\phi)-\left(z_{g} \mathrm{~W}-z_{B} B\right) \mathrm{c}(\theta) \mathrm{s}(\phi) \\
-\left(z_{g} \mathrm{~W}-z_{B} B\right) \mathrm{s}(\theta)-\left(x_{g} \mathrm{~W}-x_{B} B\right) \mathrm{c}(\theta) \mathrm{c}(\phi) \\
\left(x_{g} \mathrm{~W}-x_{B} B\right) \mathrm{c}(\theta) \mathrm{s}(\phi)-\left(y_{g} \mathrm{~W}-y_{B} B\right) \mathrm{s}(\theta)
\end{array}\right](5)
$$

$\sin =s ; \quad \cos =c$

When the S-AUV moves, the whole liquid will be pressed with different liquid particle amplitudes, synchronized with the forced harmonic movement of the S-AUV. The incremental mass is known as the force and pressure induced moment that is generated by the forced harmonic movement of the S-AUV and scale with the acceleration of the S-AUV. Therein, $M_{A}$ is the systemic inertial matrix of the incremental mass, $C_{A}(v)$ is the Coriolis and the hydrodynamic radial force matrix. $M_{A}$ is represented as below:

General vector of force and external torque $\tau_{R B}$ in the equation (4) is external force acting on S-AUV which includes: 
Tuan Nguyen Van et al., International Journal of Emerging Trends in Engineering Research, 9(9), September 2021, 1217 - 1223

$$
M_{A}=-\left[\begin{array}{cccccc}
X_{\dot{u}} & 0 & X_{\dot{\mathrm{w}}} & 0 & X_{\dot{q}} & 0 \\
0 & Y_{\dot{v}} & 0 & Y_{\dot{p}} & 0 & Y_{\dot{r}} \\
Z_{\dot{u}} & 0 & Z_{\dot{\mathrm{w}}} & 0 & Z_{\dot{q}} & 0 \\
0 & K_{\dot{v}} & 0 & K_{\dot{p}} & 0 & K_{\dot{r}} \\
M_{\dot{u}} & 0 & M_{\dot{\mathrm{w}}} & 0 & M_{\dot{q}} & 0 \\
0 & N_{\dot{v}} & 0 & N_{\dot{p}} & 0 & N_{\dot{r}}
\end{array}\right]
$$

Since $M_{A}$ is independent of the wave frequency (with low frequency) so it can be assumed that $M_{A}>0$ is a positive constant to apply in controlling.

Coriolis and the hydrodynamic radial force matrix $C_{A}(v)$ :

$$
C_{A}(v)=\left[\begin{array}{cccccc}
0 & 0 & 0 & 0 & a_{3} & -a_{2} \\
0 & 0 & 0 & -a_{3} & 0 & a_{1} \\
0 & 0 & 0 & a_{2} & -a_{1} & 0 \\
0 & a_{3} & -a_{2} & 0 & b_{3} & -b_{2} \\
-a_{3} & 0 & a_{1} & -b_{3} & 0 & b_{1} \\
a_{2} & -a_{1} & 0 & b_{2} & -b_{1} & 0
\end{array}\right]
$$

Therein:

$$
\begin{aligned}
& a_{1}=X_{\dot{u}} u+X_{\dot{\mathrm{w}}} \mathrm{W}+X_{\dot{q}} q \\
& a_{2}=Y_{\dot{v}} v+Y_{\dot{p}} p+Y_{\dot{r}} r \\
& a_{3}=Z_{\dot{u}} u+Z_{\dot{\mathrm{w}}} \mathrm{W}+Z_{\dot{q}} q \\
& b_{1}=K_{\dot{v}} v+K_{\dot{p}} p+K_{\dot{r}} r \\
& b_{2}=M_{\dot{u}} u+M_{\dot{\mathrm{w}}} \mathrm{W}+M_{\dot{q}} q \\
& b_{3}=N_{\dot{v}} v+N_{\dot{p}} p+N_{\dot{r}} r
\end{aligned}
$$

Therefore $\tau_{A}$ is given by the below equation:

$$
\tau_{A}=-\left(M_{A} \dot{v}+C_{A}(v) v\right)
$$

In addition to radiation induced potential attenuation, other attenuations such as surface friction, deterioration of wave drift and current attenuation should be considered:

$$
\tau_{V}=D(v) v
$$

Damping matrix $D(v)$ is given by:

$$
D(v)=\left[\begin{array}{cccccc}
X_{u}+X_{u|u|}|u| & 0 & 0 & 0 & 0 & 0 \\
0 & Y_{v}+Y_{v|v|}|v| & 0 & 0 & 0 & 0 \\
Z_{0}|u| & 0 & Z_{\mathrm{w}}+Z_{\mathrm{w}|\mathrm{w}|}|\mathrm{w}| & 0 & 0 & 0 \\
0 & 0 & 0 & K_{p}+K_{p|p|}|p| & 0 & 0 \\
M_{0}|u| & 0 & 0 & 0 & M_{q}+M_{q|q|}|q| & 0 \\
0 & 0 & 0 & 0 & 0 & N_{r}+N_{r|r|}|r|
\end{array}\right]
$$

$$
X_{u|u|}|u|, Y_{v|v|}|v|, Z_{\mathrm{w}|\mathrm{w}|}|\mathrm{w}|, K_{p|p|}|p|, M_{q|q|}|q| \text { và }
$$
$N_{r|r|}|r|$ are the quadratic damping factors.

$Z_{0}|u|$ và $M_{0}|u|$ is the effect which causes by the asymmetry on the $O-x y$ plane.

$\tau^{*}$ vector represents force and pushing moment as below:

$$
\tau^{*}=\tau_{R B}+\tau_{g}+\tau_{V}-\tau_{A}
$$

Since the team built the S-AUV model in the laboratory according to the ideal model, so the static force vector $\tau_{g}$ was ignored. So:

$$
\tau^{*}=\tau_{R B}+\tau_{V}-\tau_{A}
$$

To replace (2), (10) and (9) in the equation (12):

$$
M \dot{v}+C(v) v+D(v) v=\tau^{*}
$$

Therein:

$$
\begin{aligned}
& M=M_{R B}+M_{A} \\
& C(v)=C_{R B}(v)+C_{A}(v) \\
& D(v)=D(v)
\end{aligned}
$$

The motion equation of S-AUV consists of 6 degrees of freedom which is expressed through the forces and moments as follows:

$$
\begin{aligned}
& m\left[\dot{u}-v r+\mathrm{w} q-x_{g}\left(q^{2}+r^{2}\right)+y_{g}(p q-\dot{r})+z_{g}(p r+\dot{q})\right]=X \\
& m\left[\dot{v}-\mathrm{w} p+\mathrm{ur}-y_{g}\left(r^{2}+p^{2}\right)+z_{g}(p r-\dot{p})+x_{g}(q p+\dot{r})\right]=Y \\
& m\left[\dot{\mathrm{w}}-u q+v p-z_{g}\left(q^{2}+p^{2}\right)+x_{g}(r p-\dot{q})+y_{g}(r q+\dot{p})\right]=Z \\
& I_{x x} \dot{p}+\left(I_{z z}-I_{y y}\right) q r+m\left[y_{g}(\dot{\mathrm{w}}-u q+v p)-z_{g}(\dot{v}-\mathrm{w} p+\mathrm{ur})\right]=K \\
& I_{y y} \dot{q}+\left(I_{x x}-I_{z z}\right) r p+m\left[z_{g}(\dot{u}-v r+\mathrm{w} q)-x_{g}(\dot{\mathrm{w}}-u q+v p)\right]=M \\
& I_{z z} \dot{r}+\left(I_{y y}-I_{x x}\right) q p+m\left[x_{g}(\dot{v}-\mathrm{w} q+\mathrm{ur})-y_{g}(\dot{u}-v r+\mathrm{w} q)\right]=N
\end{aligned}
$$

Therein:

$X_{u}, Y_{v}, Z_{\mathrm{w}}$,

$K_{p}, M_{q}$ và $N_{r}$ are the linear damping factors. 
Tuan Nguyen Van et al., International Journal of Emerging Trends in Engineering Research, 9(9), September 2021, 1217 - 1223

\section{SIMULATION RESULTS}

\subsection{CFD analysis results}

The CFD analysis module provided with ANSYS-CFX is easy to use and allows solutions to analyze the velocity and pressure around the S-AUV body in the case of opening and closing the wings. Test conditions as Table 4.

Table 4: CFD analysis conditions

\begin{tabular}{|l|l|}
\hline \multicolumn{1}{|c|}{ Parameters } & \multicolumn{1}{c|}{ Value } \\
\hline Size of the test tank & $2 \mathrm{~m} \times 1.8 \mathrm{mx} 1.2 \mathrm{~m}$ \\
\hline Turbulent flow model & $\mathrm{k}-\varepsilon$ model \\
\hline Reynolds Number & $8.73 \times 10^{6}-6.11 \times 10^{6}$ \\
\hline Angle of attack & $0^{\circ}$ \\
\hline Velocity & $0.5 \mathrm{~m} / \mathrm{s} ; 1.0 \mathrm{~m} / \mathrm{s}, 1.5 \mathrm{~m} / \mathrm{s}$ \\
\hline
\end{tabular}

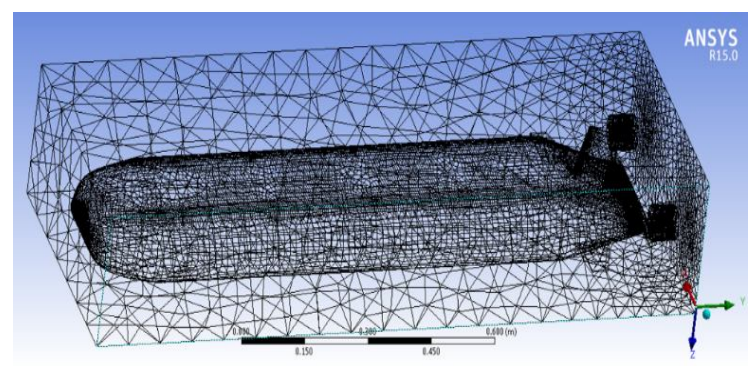

Figure 4. Meshing model S-AUV when wings close

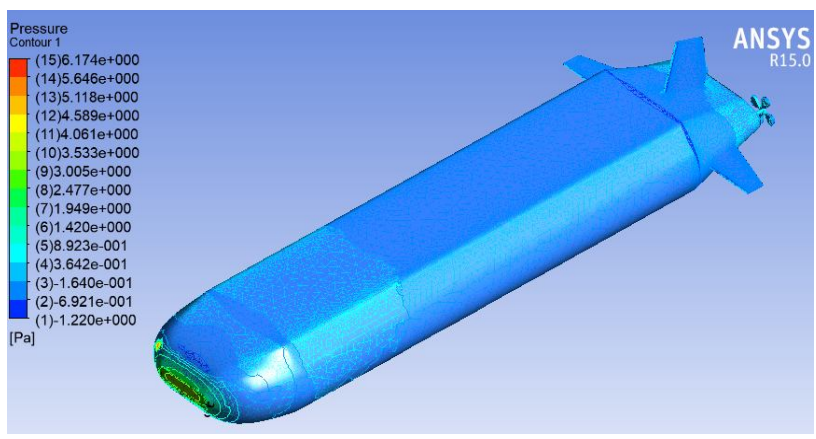

Figure 5: Dynamic pressure case wings close

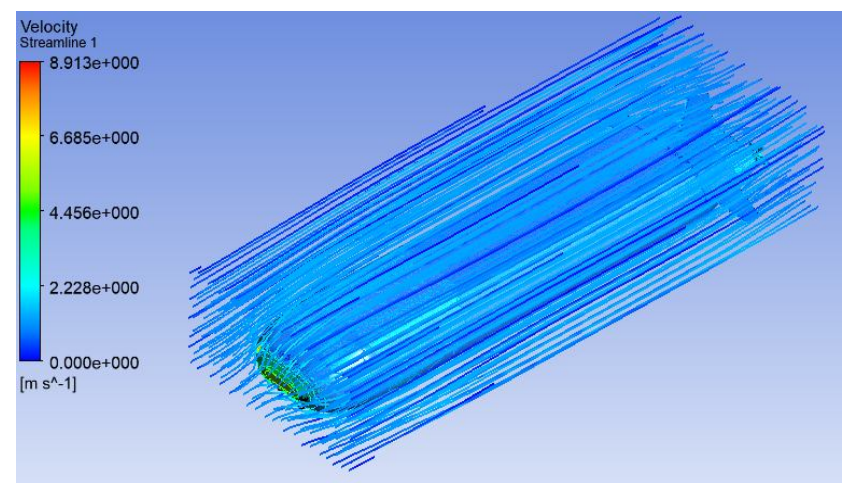

Figure 6: Velocity field case wings close

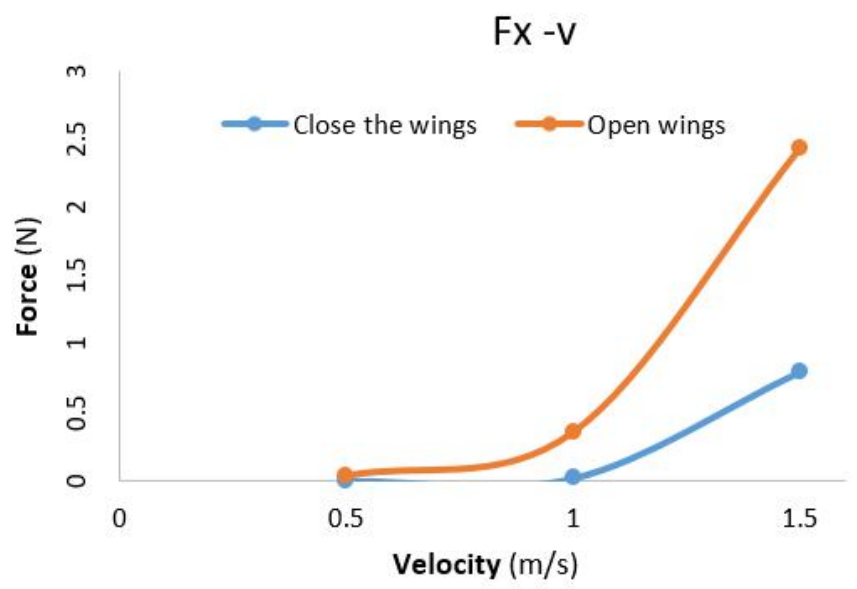

Figure 7: Chart relationship Fx - v

Fy-V

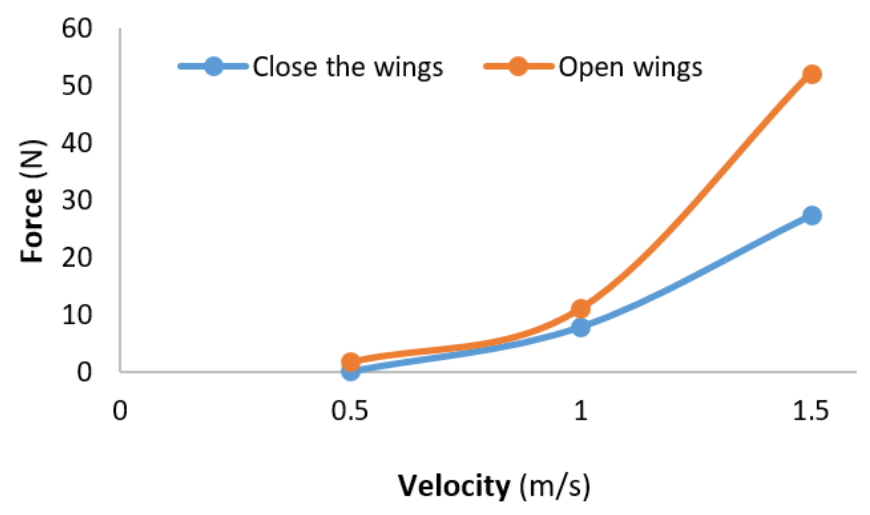

Figure 8: Chart relationship Fy - v

\section{Fz-V}

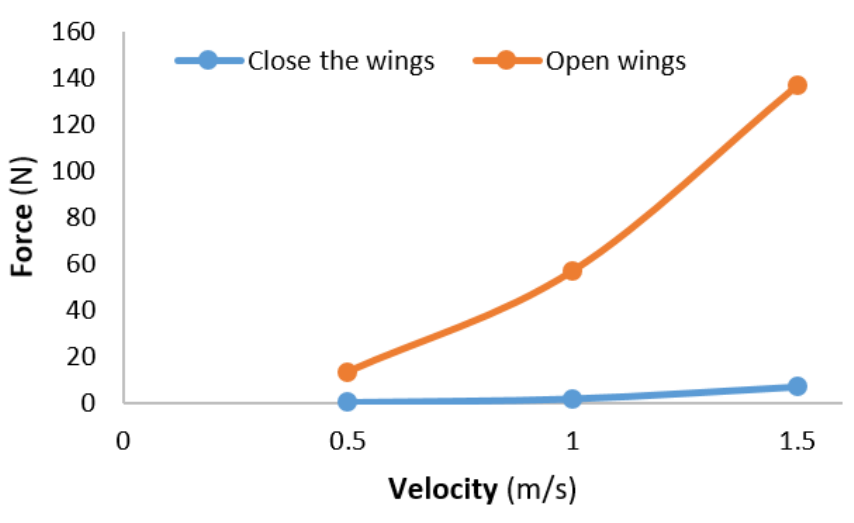

Figure 9: Chart relationship $\mathrm{Fz}-\mathrm{v}$

Results obtained after analysis using ANSYS-CFD tool. The drag in the case of wing open is always greater than the wing close. We find that the drag and lift components in both the open and closed cases increase with increasing inlet velocity. However, in the case of open wings, the drag and lift increase more. The higher the velocity, the greater the difference in drag and lift Figuge (4-9). After analysis, the parameters of the S-AUV model have been determined as in the following Table 5 . 
Tuan Nguyen Van et al., International Journal of Emerging Trends in Engineering Research, 9(9), September 2021, 1217 - 1223

Table 5: Modeling parameter S-AUV

\begin{tabular}{|c|c|c|c|c|c|}
\hline$m$ & 18.5 & $Y_{r}$ & -1.03 & $X_{\dot{\mathrm{w}}}$ & $-1.13 \times 10^{-}$ \\
\hline$x_{g}, y_{g}$ & 0.15 & $Y_{\dot{v}}$ & -0.85 & $N_{\dot{v}}$ & 0.32 \\
\hline$z_{g}$ & 0 & $Y_{v|v|}$ & -0.62 & $N_{\dot{r}}$ & -2.15 \\
\hline$X_{u}$ & 6.53 & $Z_{w}$ & 4.57 & $I_{z}$ & 1.57 \\
\hline$Z_{u|u|}$ & -0.58 & $Z_{\dot{u}}$ & 0.32 & $N_{r|r|}$ & $0.5 \times 10^{-6}$ \\
\hline \multirow[t]{2}{*}{$Y_{v}$} & 0.08 & $N_{r}$ & -12.32 & $X_{\dot{u}}$ & $6.83 \times 10^{-6}$ \\
\hline & & & & $Z_{\dot{w}}$ & $\begin{array}{c}-0.32 \times 10^{-} \\
6\end{array}$ \\
\hline
\end{tabular}

\subsection{Testing the ability to collect solar energy}

The S-AUV has been tested to collect solar energy at some localities such as Hai Phong City, Quang Ninh Province and Hanoi City, Vietnam as Figure 10.

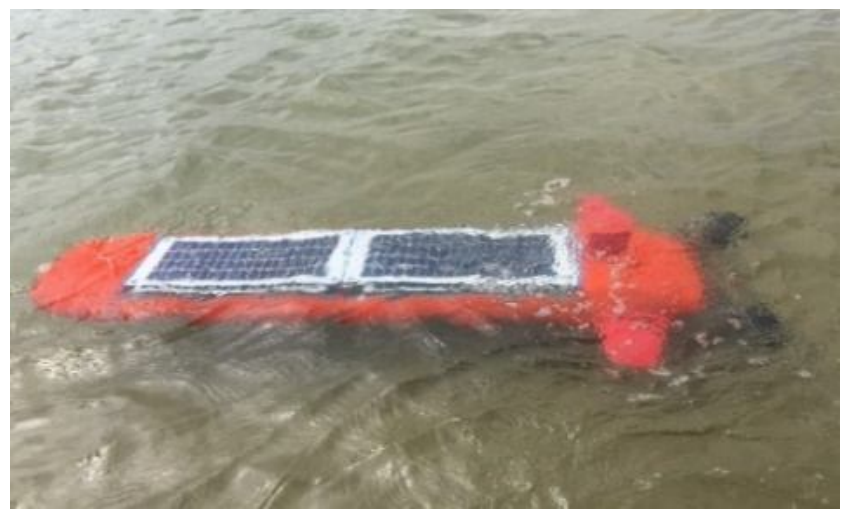

Figure 10: Testing in Quang Ninh Province, Vietnam

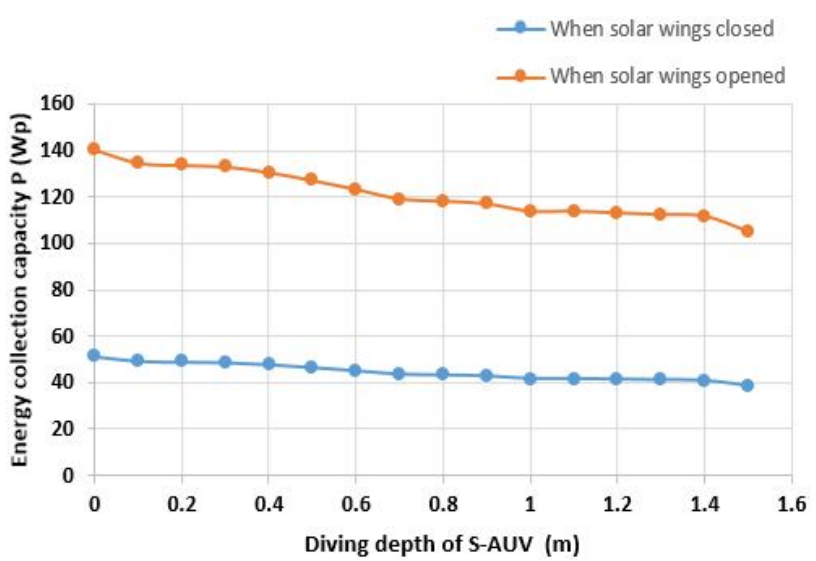

Figure 11: Solar energy collection chart when solar wing closes and opens at Hai Phong City, Vietnam (2020 Aug)

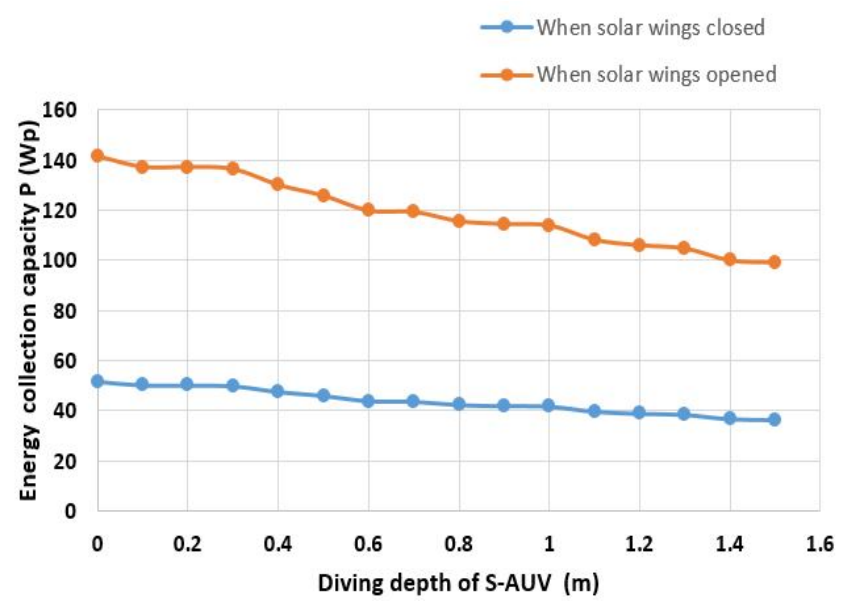

Figure 12: Solar energy collection chart when solar wing closes and opens at Quang Ninh City, Vietnam (2020 Aug)

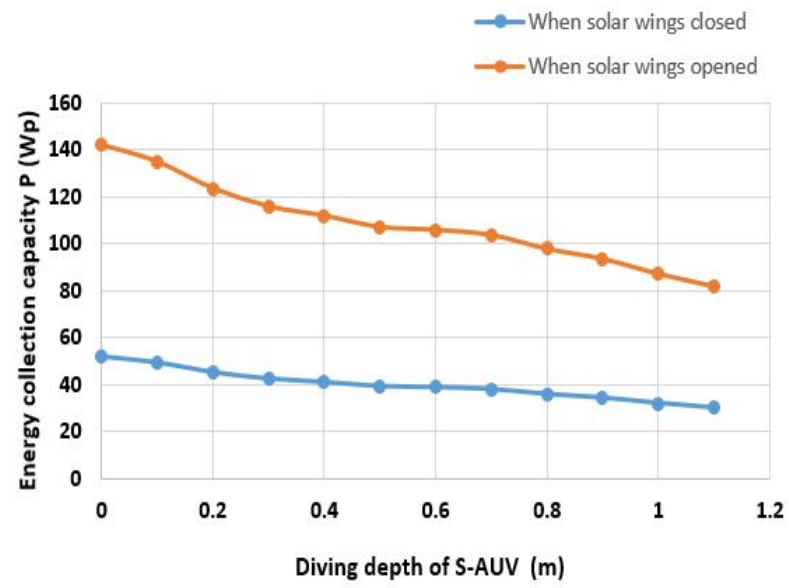

Figure 13: Solar energy collection chart when solar wing closes and opens at Ha Noi City, Vietnam (2020 Aug)

Figures $(11,12,13)$ show that when S-AUV increases the depth of diving, the solar collecting capacity of S-AUV in both fields when opening and closing the energy wing decreases linearly. Opening the retractable energy wing, the solar collector capacity increases, the largest increase is 2.7 times.

\section{CONCLUSION}

The design of the solar wing is able to open and close reduce the drag, lift and moment when S-AUV operation. The solar wing will be opened when collecting solar energy and closed when moving. In the future, the author will study, design and manufacture a S-AUV with the presented design to evaluate the energy efficiency in some areas of Vietnam. The paper presents an Autonomous Underwater Vehicles with solar energy supplemented. Applying the analysis and experimental results, when collecting solar energy, the S-AUV floats as close to the water surface as possible. Especially, when integrating retractable solar wing increases the solar collector capacity when the S-AUV's energy wing is opened to about 2.7 times compared to the closed solar wing. With the dynamic parameters of the S-AUV model, have been 
Tuan Nguyen Van et al., International Journal of Emerging Trends in Engineering Research, 9(9), September 2021, 1217 - 1223

determined. Upcoming, the author group will build an intelligent controllers to control the designed S-AUV model.

\section{ACKNOWLEDGEMENT}

The authors are very grateful to Hanoi University of Science and Technology and Phenikaa University, Vietnam, for their assistance in this research work.

\section{REFERENCES}

1. Lee, Eddy, Robert, A. High-resolution geological AUV survey results across a portion of the eastern Sigsbee Escarpment. AAPG Bulletin, 86, 747-764, 2004.

2. Blidberg, J. Yuh, Giacomo Marani, D. Richard. Applications of marine robotic vehicles, Intelligent Service Robotics, 4, 221-231, 2011.

3. Bradley. A.M, Feezor. M.D, Singh. H, Sorrell. F. Yates. Power systems for autonomous underwater vehicles. IEEE Journal of Oceanic Engineering, 26, 526-538, 2001.

4. Alejandro Mendez, Teresa J. Leo and Miguel A. Herreros. Fuel cell power systems for autonomous underwater vehicles: state of the art, in $1 s t$ International e-Conference on Energies, 18 March 2014

5. Swider-Lyons, Karen E.; et al. Technical Issues and Opportunities for Fuel Cell Development for Autonomous Underwater Vehicles, in Proceedings of the 2002 Workshop on Autonomous Underwater Vehicles, IEEE, 2. P 200. 0-7803-7572-6, 2002.

6. Albert M. Bradley, Michael D. Feezor, Hanumant Singh, and F. Yates Sorrell. Power Systems for Autonomous Underwater Vehicles, IEEE journal of oceanic engineering, vol. 26, no. 4, october 2001.

7. N. Sulaiman, M. Hannan, A. Mohamed, E. Majlan, and W. W. Daud. A review on energy management system for fuel cell hybrid electric vehicle: Issues and challenges, Renewable and Sustainable Energy Reviews, vol. 52, no. Supplement C, pp. 802 - 814, 2015.

8. Ali Razmjoo, Mohammad Ghadimi, Mehrzad Shams, Hoseyn Shirmohammadi. Design and Built a Research AUV Solar Light Weight, International Journal of Energy and Power Engineering, pp268-274, 2015.

9. Orhan Ekren and Banu Yetkin Ekren. Size Optimization of a Solar-wind Hybrid Energy System Using Two Simulation Based Optimization Techniques, Environmental Science, 2011.

10. D. Richard Blidberg, Mikhail D. Ageev, James C. Jalbert. Some Design Considerations for a Solar Powered AUV; Energy Management and its Impact on Operational Characteristics, Unmanned Untethered Submersible Technology, Sept. 7-10, 1997.

11. Karthik Reddy Buchireddy Sri, Poondla Aneesh, Kiran Bhanu, M Natarajan. Design Analysis of Solar-Powered Unmanned Aerial Vehicle, J. Aerosp. Technol. Manag. 8 (4) • Oct-Dec 2016.

12. Jalbert, J.C., Iraqui-Pastor, P, Miles, S, Blidberg, D.R., James, D.,Ageev, M. D. Solar AUV Technology
Evaluation Program, in Proceedings 10th International Symposium on Unmanned Untethered Submersible Technology, Autonomous Undersea Systems Institute, Durham, NH, 1997.

13. A. Guerrero $\square$ González, F. García $\square$ Córdova and F. de Asis Ruz $\square$ Vila. A Solar Powered Autonomous MobileVehicle for Monitoring and Surveillance Missions of Long Duration, International Review of Electrical Engineering, Part A, vol. 5, Issue: 4, pp. $1580 \square 1587$, August 2010.

14. Nishi, Y., Kashiwagi, M., Koterayama, W., Nakamura, M., Samuel, S.Z.H., Yamamoto, I. and Hyakudome, T., Resistance and Propulsion Performance of an Underwater Vehicle Estimated by a CFD Method and Experiment, ISOPE '07, Lisbon, Spain. 2007.

15. Jagadeesh, Murali. Explicit Dynamic Analysis of Industrial Helmet Manufactured Using Bamboo and Vakka Fiber Composite, International Journal of Emerging Trends in Engineering Research (IJETER), Volume 8, No.5, May 2020.

16. Shahid, Huang. Computational fluid dynamics based bulbous bow optimization using a genetic algorithm, J. Marine Sci. Appl. 11 (3), pp286-294 , 2012.

17. ANSYS Inc, ANSYS CFX-Solver Theory Guide: Release 12.0, ANSYS Ltd. pp. 46-87, 2009.

18. . Hoerner, S.F., Fluid-Dynamic Drag, Hoerner Fluid Dynamics, Brick Town, N.J. 1965.

19. T. I. Fossen, O.-E. Fjellstad. Nonlinear modelling of marine vehicles in 6 degrees of freedom. Mathematical Modelling of Systems, vol. 1 no. 1, pp. 17-27, 1995. 